This document is the unedited Author's version of a Submitted Work that was subsequently accepted for publication in 'ACS Sustainable Chemistry \& Engineering', copyright $@$ American Chemical Society after peer review. To access the final edited and published version see:https://pubs.acs.org/doi/abs/10.1021/es035444k

\title{
Dark Oxidation of Dissolved and Liquid Elemental Mercury in Aquatic Environments
}

\author{
MARC AMYOT,FR A N Ç OIS M.M.MOREL, ANDPARIS A A. ARIYA
}

Elementalmercury $\left(\mathrm{Hg}^{0}\right)$ canbefoundinliquidordissolved forms in aquatic systems. Whereas dissolved $\mathrm{Hg}^{0}$ is measured in virtually all aquatic systems, liquid $\mathrm{Hg}^{0}$ droplets are mainly observed at poorly lit sediment/water interfaces of ecosystems withlocal point sources suchas hydrothermal vents, gold extraction sites, and near industrial facilities. Here, wereportthat,inthedark, liquidanddissolved forms of $\mathrm{Hg}$ behave

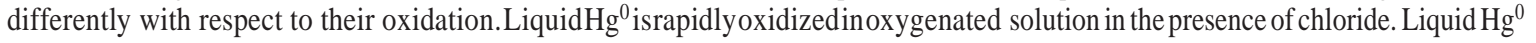
oxidation ratesarepositivelycorrelatedwithchlorideconcentrations and droplet surface area. When liquid $\mathrm{Hg}$ is removed fromsolution,the oxidationstopseventhoughthesolution isstillsaturated withdissolved $\mathrm{Hg}^{0}$. $\mathrm{LiquidHg}^{0}$ droplets

in oxygenated marineorbrackishenvironments should be oxidized andrelease $\mathrm{Hg}^{2+}$ to solution. Infreshwatersor anoxic seawater, liquid $\mathrm{Hg}$ will dissolvereleasing $\mathrm{Hg}_{\mathrm{aq}}{ }^{0}$ which, itself, will slowly oxidize.

\section{Introduction}

Elemental mercury, $\mathrm{Hg}^{0}$, can be found in liquid or dissolved forms in aquatic ecosystems. Dissolved $\mathrm{Hg}^{0}$ is ubiquitous and usually shows higher concentrations near the surface, as aresult of photoreduction of $\mathrm{Hg}(\mathrm{II})(1) . \mathrm{Liquid}^{\mathrm{H}} \mathrm{Hg}^{0}$ is rarely observed in uncontaminated fresh or marine waters but may be present near local point sources. Typical examples include the release of liquid $\mathrm{Hg}$ in rivers and estuaries by gold mining activities (2). Offshore submarine hydrothermal vents have also been identified as significant sources of liquid $\mathrm{Hg}$ to the seafloor (3). In contrast to dissolved $\mathrm{Hg}^{0}$, elemental $\mathrm{Hg}$ droplets are only found in sediments and at sediment/water interfaces. These environments are typically poorly lit and unlikely to be affected by photochemical processes.

Elemental $\mathrm{Hg}$ is the main volatile form of $\mathrm{Hg}$ in natural waters (4-6). The formation of volatile dissolved mercury favors the removal of $\mathrm{Hg}$ from lakes and ocean through gas evasion. On a local scale, this may be significant in the regulation of $\mathrm{Hg}$ accumulation in aquatic wildlife by de creasing the $\mathrm{Hg}$ burden in the water column at a given site and by limiting the amount of $\mathrm{Hg}$ available for methylation and bioaccumulation. On a global scale, $\mathrm{Hg}^{0} \mathrm{evasion}$ from the ocean surface constitutes a significant part of the global $\mathrm{Hg}$ cycle, accounting for about $40 \%$ of the current total flux of $\mathrm{Hg}$ to the atmosphere (7). It is therefore important to understand the processes leading to the formation of dissolved $\mathrm{Hg}^{0}$ and to its oxidation.

While $\mathrm{Hg}(\mathrm{II})$ reduction in the aquatic environment has been relatively well studied (8-13), there is limited information on $\mathrm{Hg}^{0}$ oxidation. Some field studies have suggested that dark oxidation of dissolved $\mathrm{Hg}^{0}$ occurs in lakes (14) and coastal waters (11). Lalonde et al. (15-16) have shown that this oxidation is greatly enhanced by solar radiation, particularly UVB radiation, and by chloride. Photooxidation rates were not affected by oxygen concentrations and did not decrease when samples were heat-sterilized, treated with chloroform, or filtered prior to exposure to light. Laboratory experiments have also shown that drops of liquid $\mathrm{Hg}^{0}$ are oxidized when placed in water in the presence of chloride or thiol compounds and oxygen (17-21), whereas only limited oxidation occurs in the absence of chloride. However, these laboratory studies did not distinguish between oxidation at the surface of the liquid $\mathrm{Hg}^{0}$ and of the dissolved $\mathrm{Hg}^{0}$ at equilibrium with the liquid. To understand the potential fate of liquid $\mathrm{Hg}^{0}$ in the environment, we need to quantify its rates of surface oxidation and dissolution and compare them to the rate of oxidation of dissolved $\mathrm{Hg}^{0}$

The main objective of this study is to assess the differences in the oxidation of liquid and dissolved $\mathrm{Hg}^{0}$ in aquatic environments. Since liquid droplets are mainly found in poorly lit environments (i.e., sediments and sediment/water interfaces), our focus here is on $\mathrm{Hg}$ oxidation in the dark. The specific goals are (a) to determine if oxidation of liquid $\mathrm{Hg}^{0}$ occurs under the same conditions of salinity and oxygenation as oxidation of dissolved $\mathrm{Hg}^{0}$ and (b) to compare the rates of oxidation and dissolution of liquid $\mathrm{Hg}^{0}$ with the rate of oxidation of dissolved $\mathrm{Hg}^{0}$.

\section{Experimental Section}

Experiments with Dissolved $\mathbf{H g}^{0}$. Solutions of dissolved $\mathrm{Hg}^{0}$ were prepared by bubbling $\mathrm{N}_{2}$ or $\mathrm{O}_{2}$ containing $\mathrm{Hg}^{0}$ vapor through Milli-Q water (Millipore). The gas was initially enriched with $\mathrm{Hg}^{0}$ vapor by letting it flow over a drop of liquid $\mathrm{Hg}$ (ACS reagent grade, Aldrich, Milwaukee, WI) placed at the bottom of a U-shaped glass tube. The drop was prevented from moving downstream by a glass frit. The concentrations of dissolved mercury obtained by this method were in the 20-100 nM range. This solution was then diluted 1:10 in Milli-Q water to yield a final concentration in the 2-10 nM range. This range of concentrations is higher than what is usually observed in aquatic environments. However, this range is appropriate when considering dissolved $\mathrm{Hg}^{0}$ levels likely to be observed in water overlying $\mathrm{Hg}$ droplets at sediment/water interfaces. All experiments were conducted in a reaction vessel containing $100 \mathrm{~mL}$ of solution.

Concentrations of dissolved $\mathrm{Hg}^{0}$ and of total $\mathrm{Hg}\left(\mathrm{Hg}_{\mathrm{T}}\right)$ were followed over time (ranging from 2 to $6 \mathrm{~h}$ ) in the diluted solution, under different concentrations of oxygen (hypoxic and saturated conditions), chloride $(0,5$, and $500 \mu \mathrm{M})$, and hydrogen ions (at pH 5 and 7).

Dissolved $\mathrm{Hg}^{0}$ analysis was performed by transferring $0.1 \mathrm{~mL}$ from the solution to a bubbler containing $300 \mathrm{~mL}$ of purged water and by bubbling for 12 min using a flow of purified Argon. The $\mathrm{Hg}^{0}$ transferred to the gas phase was then collected 
This document is the unedited Author's version of a Submitted Work that was subsequently accepted for publication in 'ACS Sustainable Chemistry \& Engineering', copyright @ American Chemical Society after peer review. To access the final edited and published version see:https://pubs.acs.org/doi/abs/10.1021/es035444k

on a gold wire trap (Brooks Rand, WA). Three gold traps were used for collection during this study. Their collection efficiency was routinely monitored and exceeded $90 \%$. The collection traps were then placed in ultrahigh purity argon gas stream and the $\mathrm{Hg}$ was released by heating and recaptured by a second gold wire trap (double gold amalgamation technique). This second trap was heated and the released $\mathrm{Hg}$ was measured by an atomic fluorescence detector (Tekran $\mathrm{Hg}$ analyzer, model 2500, Canada). Calibrations were made using liquid standards or by injecting known amounts of gaseous

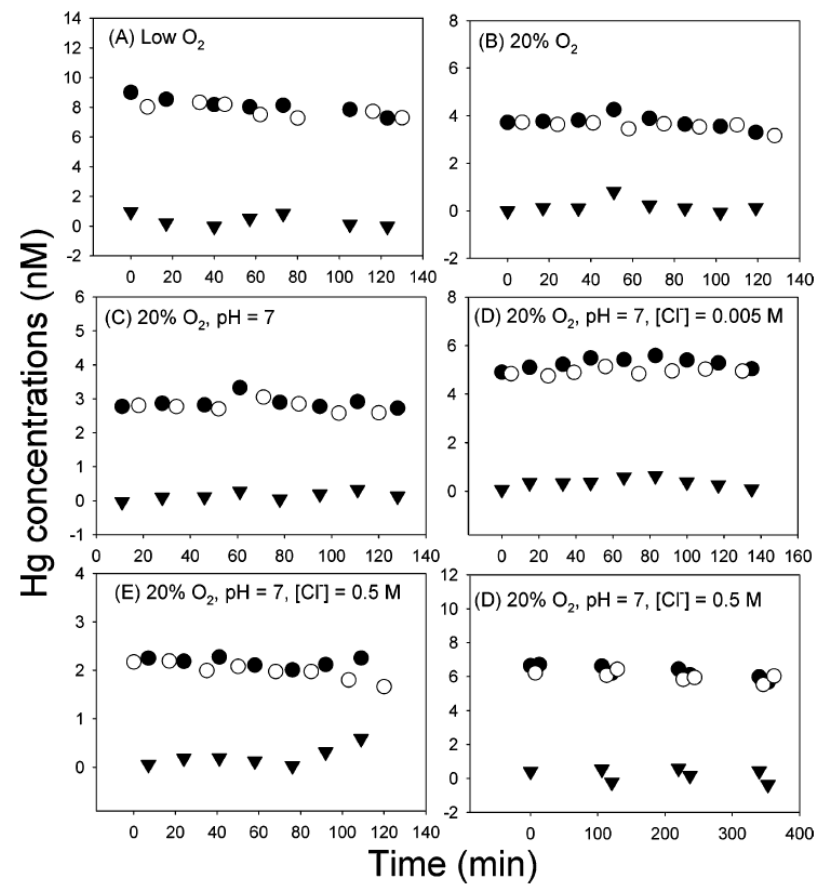

FIGURE 1. Time series of $\mathrm{Hg}^{0}$ (open circles), $\mathrm{Hg}$ (closed squares), and $\mathrm{Hg}(\mathrm{I}+\mathrm{II})$ (closed triangles) concentrations in Milli- $\mathrm{O}$ water, at different concentrations of chloride and oxygen. $20 \% \mathrm{O}_{2}$ indicates that the samples are in equilibrium with air and dissolved oxygen is near saturation in solution. $\mathrm{Hg}(\mathrm{I}+\mathrm{II})$ concentrations were calculated by the difference between $\mathrm{Hg}_{\mathrm{T}}$ and $\mathrm{Hg}^{0}$.

$\mathrm{Hg}^{0}$ in the analytical line. Both methods yielded similar calibration curves. The detection limit of this method (calculated as 3 times the standard deviation of 10 low-level samples) was $0.06 \mathrm{nM}$.

For $\mathrm{Hg}_{\mathrm{T}}$, the $\mathrm{pH}$ of the sample was increased by addition of $1 \mathrm{~mL} \mathrm{NaOH} \mathrm{(4} \mathrm{M).} \mathrm{All} \mathrm{the} \mathrm{Hg}$ was then immediately converted to $\mathrm{Hg}^{0}$ using $\mathrm{NaBH}_{4}\left(1 \mathrm{~mL}\right.$ of $\left.1 \% \mathrm{NaBH}_{4} \mathrm{w} / \mathrm{v}\right)$ as a reducing agent (22). The sample was then bubbled and $\mathrm{Hg}$ was measured as dissolved $\mathrm{Hg}^{0}$. All glassware was thoroughly cleaned in acid and gloves were worn at all times. The detection limit of this method (calculated as 3 times the standard deviation of 10 low-level samples) was $0.04 \mathrm{nM}$.

Experiments with Liquid $\mathbf{H g}^{0}$. A drop of $\mathrm{Hg}^{0}$ (Fisher; $0.1 \mathrm{~mL}$ ) was placed in a 100-mL solution of Milli-Q water buffered at different $\mathrm{pHs}$. Concentrations of dissolved $\mathrm{Hg}^{0}$ and $\mathrm{Hg}_{\mathrm{T}}$ were followed over time at different dissolved oxygen $(0.70$ and $\left.8.85 \mathrm{mg} \mathrm{L}^{-1}\right)$ and chloride concentrations in solution $(0,5,50$, and $500 \mu \mathrm{M})$. We also investigated the effect of the size of the mercury droplet $(0.011,0.024$, and $0.100 \mathrm{~mL})$ on $\mathrm{Hg}$ oxidation over time, at constant chloride and oxygen levels. The effect of removing the $\mathrm{Hg}$ droplet after a 1-h exposure to a salted buffered and oxygenated solution was also studied. At these nanomolar concentrations of $\mathrm{Hg}^{0}$, newly formed $\mathrm{Hg}$ (II) can potentially disproportionate into $\mathrm{Hg}{ }^{2+}$, since the disproportionation constant is about $5.2 \mathrm{nM}$ at $25^{\circ} \mathrm{C}(23)$. We thus consider that the difference between the concentrations of total and elemental $\mathrm{Hg}$ corresponds to the sum of $[\mathrm{Hg}(\mathrm{I})]$ and $[\mathrm{Hg}(\mathrm{II})]$, referred below as $\mathrm{Hg}(\mathrm{I}+\mathrm{II})$.

\section{Results and Discussion}

The oxidation of dissolved $\mathrm{Hg}^{0}$ in the presence and absence of oxygen and chloride and at different pHs was followed over time (Figure 1). Dissolved $\mathrm{Hg}^{0}$ was not rapidly oxidized by $\mathrm{O}_{2}$ and chloride. These results contrast with those of Magalhães and Tubino (18) and Yamamoto (20) which showed an oxidation of droplets of liquid $\mathrm{Hg}^{0}$ under similar conditions. They do agree with results obtained by Lalonde et al. $(15,16)$, in which brackish waters kept in the dark did not show a significant loss of dissolved $\mathrm{Hg}^{0}$ over time. It is therefore likely that liquid $\mathrm{Hg}^{0}$ is $\mathrm{more}$ readily oxidized in the dark than dissolved $\mathrm{Hg}^{0}$.

Weobservedindeed arapid oxidation of liquid $\mathrm{Hg}^{0}$ in the presence of chloride (Figure 2). After addition of $\mathrm{KCl}$, $\mathrm{Hg}$ (II) levels increased at a rate of $13.5 \mathrm{nM} \mathrm{min}^{-1}(r=0.99 ; p<0.001 ; n=5)$. The drop of $\mathrm{Hg}$ was then removed and oxidation of $\mathrm{Hg}^{0}$ stopped immediately, even though approximately $200 \mathrm{nM}$ of dissolved $\mathrm{Hg}^{0}$ was still in solution. The 
This document is the unedited Author's version of a Submitted Work that was subsequently accepted for publication in 'ACS Sustainable Chemistry \& Engineering', copyright $(\odot)$ American Chemical Society after peer review. To access the final edited and published version see:https://pubs.acs.org/doi/abs/10.1021/es035444k

chloride dependency of liquid $\mathrm{Hg}$ oxidation was further evidenced by changes in $\mathrm{Hg}$ oxidation rates when we varied the concentration of sodium chloride over 3 orders of magnitude (Figure 3A), in a solution equilibrated with ambient air and containing a $0.1-\mathrm{mL}$ droplet of $\mathrm{Hg}^{0}$. At the lowest $\left[\mathrm{Cl}^{-}\right](5 \mathrm{mM})$, the rate of $\mathrm{Hg}$ (II) production was similar to the one observed in the absence of chloride (Figure 3B). At higher $\left[\mathrm{Cl}^{-}\right](50-500 \mathrm{mM}$ ), the rate of oxidation was chloride-dependent.

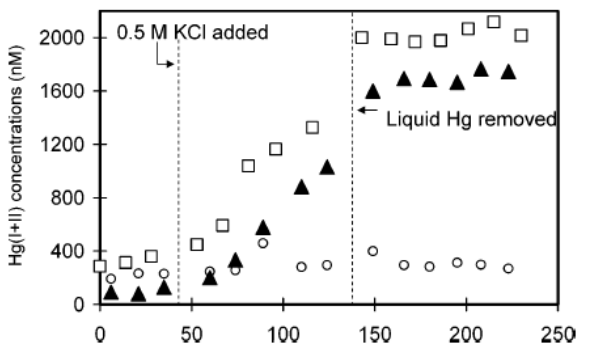

FIGURE 2. Time series of $\mathrm{Hg}^{0}$ (open circles), $\mathrm{Hg}_{\mathrm{T}}$ (open squares), and $\mathrm{Hg}(\mathrm{I}+\mathrm{II})$ (closed triangles) concentrations in Milli-0 water equilibrated with ambient air, buffered at $\mathrm{pH} 7$, in the presence of a $\mathrm{Hg}$ drop of $0.1 \mathrm{~mL}$. $\mathrm{Hg}(\mathrm{I}+\mathrm{II})$ concentrations were calculated by the difference between $\mathrm{Hg}_{\mathrm{T}}$ and $\mathrm{Hg}^{0}$. After $45 \mathrm{~min}, 0.5 \mathrm{M} \mathrm{KCl}$ was added and after $140 \mathrm{~min}$, the $\mathrm{Hg}$ drop was removed. $\mathrm{Hg}(\mathrm{I}+\mathrm{II})$ concentrations were calculated by the difference between $\mathrm{Hg}_{\mathrm{T}}$ and $\mathrm{Hg}^{0}$.
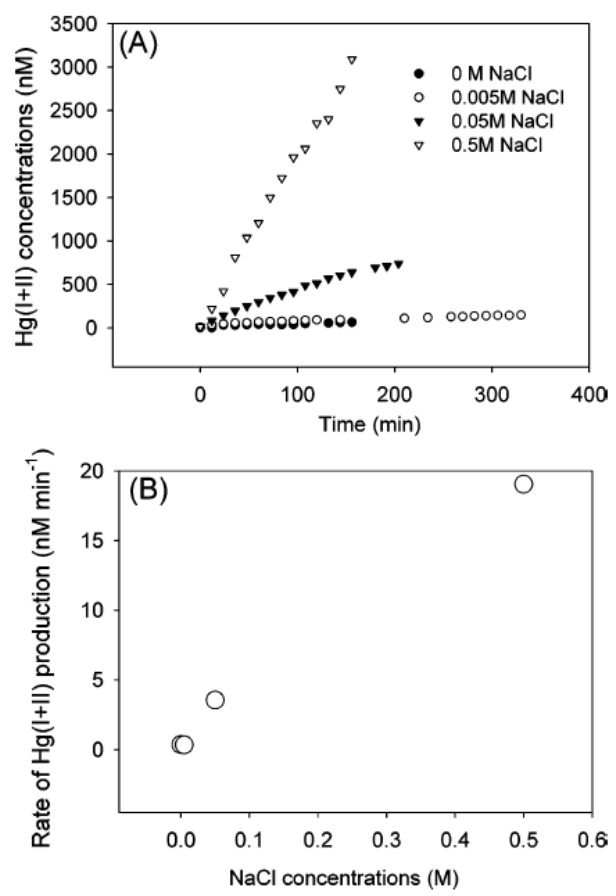

FIGURE 3. (A) Time series of $\mathrm{Hg}(\mathrm{I}+\mathrm{II})$ formation in the presence of a $0.1-\mathrm{mL} \mathrm{Hg}{ }^{0}$ droplet, as a function of different levels of $\mathrm{NaCl}(0$, $0.005,0.05,0.5 \mathrm{M})$ in a $100-\mathrm{mL}$ aqueous solution equilibrated with ambient air. (B) Relationships between rates of $\mathrm{Hg}(\mathrm{I}+\mathrm{II})$ production and different levels of $\mathrm{NaCl}$. $\mathrm{Hg}(\mathrm{I}+\mathrm{II})$ concentrations were calculated by the difference between $\mathrm{Hg}_{\mathrm{T}}$ and $\mathrm{Hg}^{0}$.
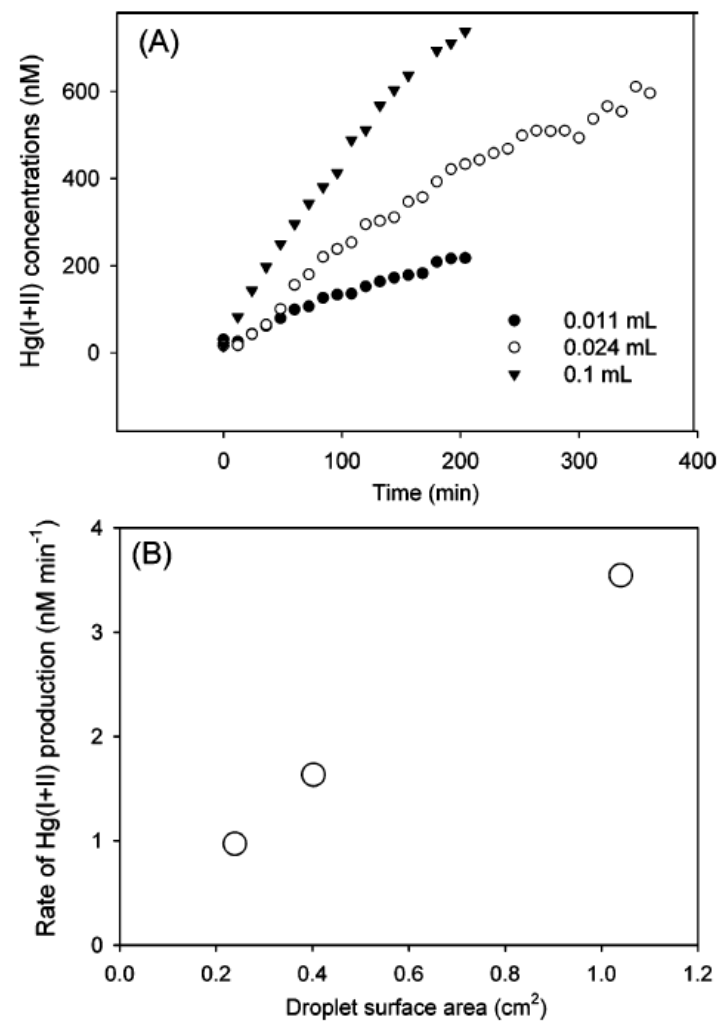

FIGURE 4. (A) Time series of $\mathrm{Hg}(\mathrm{I}+\mathrm{II})$ formation, as a function of different droplet size $(0.011,0.024,0.1 \mathrm{~mL}$ ) in a $100-\mathrm{mL}$ aqueous solution containing $0.05 \mathrm{M} \mathrm{NaCl}$, equilibrated with ambient air. (B) Relationships between rates of $\mathrm{Hg}(\mathrm{I}+\mathrm{II})$ production and different droplet surface areas. $\mathrm{Hg}(\mathrm{I}+\mathrm{II})$ concentrations were calculated by the difference between $\mathrm{Hg}_{\mathrm{T}}$ and $\mathrm{Hg}^{0}$.

Since the approximate average concentration of chloride in natural freshwaters is around $8.3 \mathrm{mg} \mathrm{L}^{-1}(0.2 \mathrm{mM}$; 24), liquid $\mathrm{Hg}^{0}$ oxidation should be slow in freshwaters. In brackish or marine water, however, this oxidation may be relatively rapid.

Since the oxidation of $\mathrm{Hg}^{\mathrm{O}}$ ceased upon removal of the liquid droplet, it appears that the interface $\mathrm{Hg}^{0}$ liquid/solution 
This document is the unedited Author's version of a Submitted Work that was subsequently accepted for publication in 'ACS Sustainable Chemistry \& Engineering', copyright @ American Chemical Society after peer review. To access the final edited and published version see:https://pubs.acs.org/doi/abs/10.1021/es035444k

plays a critical role in the process. We thus examined the effect of changing the surface area of the droplet by varying its volume over an order of magnitude $(0.01,0.02$, and $0.1 \mathrm{~mL}$; Figure $4 \mathrm{~A})$, in a $100-\mathrm{mL}$ solution equilibrated with ambient air and containing $0.05 \mathrm{M} \mathrm{NaCl}$. $\mathrm{Hg}$ oxidation was faster in the presence of the larger drop but did not increase by an order of magnitude. As expected, the production of $\mathrm{Hg}$ (II) was proportional to the droplet surface area calculated by assuming that the droplet is roughly spherical (Figure 4B).

We tested the effect of oxygen concentration on the dark oxidation of liquid $\mathrm{Hg}^{0}$ at an intermediate chloride concentration $(0.05 \mathrm{M})$. At low oxygen levels ( $8.0 \%$ saturation), $\mathrm{Hg}$ oxidation was much slower than at high oxygenlevels (99.5\% saturation), with the initial oxidation rate roughly proportional to the concentration of $\mathrm{O}_{2}$ (Figure $5 \mathrm{~A}$ ). These results are consistent with those reported by others $(18-19)$. The higher oxidation rate observed at the higher $\mathrm{O}_{2}$ concentration was matched by a markedly lower rate of dissolution of $\mathrm{Hg}^{0}$ (Figure $5 \mathrm{~B}$ ). Because this effect was observed at the onset of the experiment, it probably reflects a competition for reactive mercury atoms between the two surface processes rather than a modification of the surface by oxidation as may be seen over longer time periods (see below). Both the rate of dissolution and the rate of oxidation of liquid $\mathrm{Hg}^{0}$ slow with time (Figure 5). In dissolution, this is simply a reflection of the fact that equilibrium with the solution (ca. 200nM $\mathrm{Hg}_{\mathrm{aq}}{ }^{\circ}$ ) is being approached. However, the decreasing rate of oxidation with time must reflect a decrease in the intrinsic rate of reaction at the surface. We hypothesize that oxidation products are being formed at the surface of the droplet, hampering further oxidation of $\mathrm{Hg}^{\mathrm{O}}$ over time.

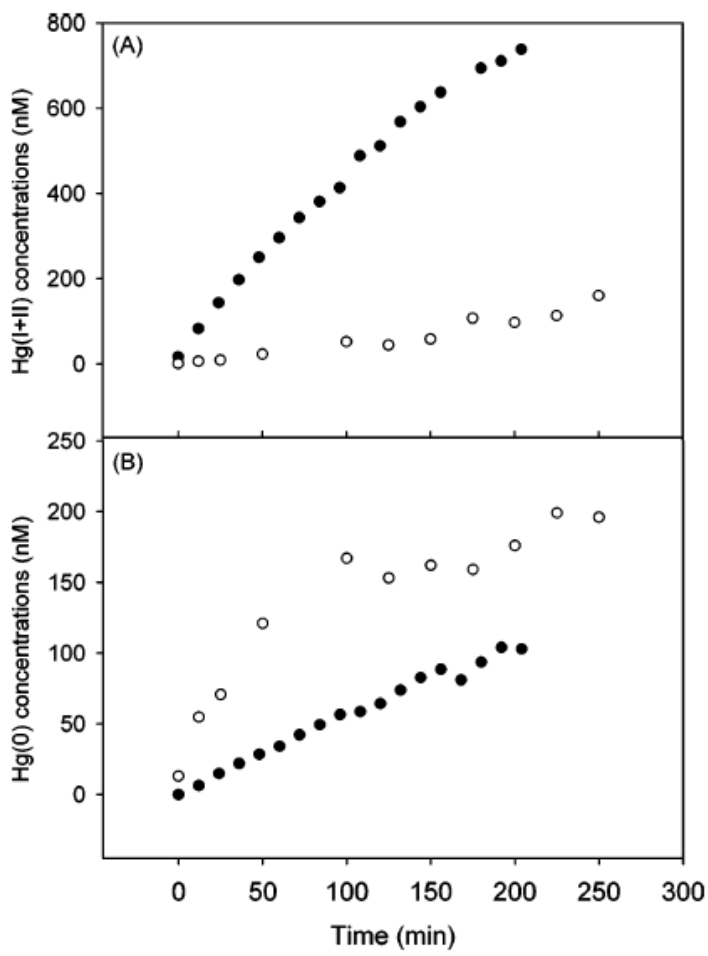

FIGURE 5. Time series of $(A) \mathrm{Hg}(\mathrm{I}+\mathrm{II})$ concentrations and $(\mathrm{B}) \mathrm{Hg}(0)$ concentrations at high $(99.5 \%$ saturation) and low ( $8.0 \%$ saturation) oxygen levels, in the presence of a $0.1-\mathrm{mL} \mathrm{Hg}^{0}$ droplet, in a $100-\mathrm{mL}$ solution containing $0.05 \mathrm{M} \mathrm{NaCl}$. $\mathrm{Hg}(\mathrm{I}+\mathrm{II})$ concentrations were calculated by the difference between $\mathrm{Hg}_{\mathrm{T}}$ and $\mathrm{Hg}^{0}$.

To compare the rate of oxidation of liquid $\mathrm{Hg}^{0}$ with that of $\mathrm{Hg}^{0}$ in solution, we need to normalize it to the number of atoms of $\mathrm{Hg}^{0}$ at the surface of the droplet. A simple calculation shows that this number is about $3(M N / m)^{2 / 3}$, where $M$ is the mass of the droplet, $m$ the atomic mass of $\mathrm{Hg}$, and $N$ Avogadro's number. The net result is that the concentration of surface atoms on a mercury droplet of $0.1 \mathrm{~mL}(1.36 \mathrm{~g})$ in a $100-\mathrm{mL}$ beaker must be approximately $10 \mathrm{nM}$. Thus, in an air-equilibrated solution at a concentration of chloride near that of seawater ( $0.5 \mathrm{M}$; see Figure 3$)$, the surface of the droplet is oxidized with an approximate first- order rate constant of $2 \mathrm{~min}^{-1}, 2-3$ orders of magnitude faster than $\mathrm{Hg}^{\mathrm{O}}$ in solution, even in the presence of solar radiation ( $k$ ranging between 0.002 and $0.015 \mathrm{~min}^{-1} ; 16$ ). The same calculation for the rate of dissolution of liquid $\mathrm{Hg}^{\mathrm{O}}$ shows that the first-order rate constant (normalized to the 
This document is the unedited Author's version of a Submitted Work that was subsequently accepted for publication in 'ACS Sustainable Chemistry \& Engineering', copyright @ American Chemical Society after peer review. To access the final edited and published version see:https://pubs.acs.org/doi/abs/10.1021/es035444k

concentration of surface atoms) is about $0.3 \mathrm{~min}^{-1}$, ap- proximately the same as the rate of oxidation in $0.05 \mathrm{MNaCl}$ (air-equilibrated). The total $\mathrm{Hg}^{0}$ concentration contributed by a $0.1-\mathrm{mL}$ droplet in a $100-\mathrm{mL}$ beaker is $68 \mathrm{mM}$, and the half-life of such a droplet is 30 years if it is subjected only to dissolution (and if the initial dissolution rate we observed is maintained by efficient diffusion/advection of the dissolved $\mathrm{Hg}^{0}$ that is produced). Oxidation in oxygenated seawater would reduce this half-life to about 5 years, if the initial rate of oxidation were maintained, (presumably by sufficient agitation of the droplet to avoid "pacification" of the surface).

Liquid $\mathrm{Hg}$ droplets are currently found (i) near sites of gold and mercury extraction, (ii) near some hydrothermal vents, and (iii) near industrial point sources. Our results indicate that drops of $\mathrm{Hg}^{0}$ should be oxidized and release $\mathrm{Hg}^{2+}$ to solution if they are present in brackish or marine oxygenated waters, such as the estuaries of rivers where gold extraction is conducted. Mercury drops present in low salinity or anoxic waters, including hydrothermal vents, should gradually dissolve, releasing $\mathrm{Hg}^{0}$ to solution. From previous experiments, we determined that dissolved $\mathrm{Hg}^{\mathrm{O}}$ can be oxidized in the dark in the presence of oxygen, chloride, and a suitable surface. In coastal systems, first-order oxidation rate constants reached values around $0.1 \mathrm{~h}^{-1}$ (11). Further research is needed to understand the role of adsorption at natural interfaces in such oxidation and to compare the resulting oxidation rates with those observed for liquid mercury.

\section{Acknowledgments}

This research was supported by grants from U.S. EPA to

F.M.M.M. and from NSERC and the Collaborative Mercury Research Network to M.A. We thank Dominic Bélanger for his analytical contribution.

\section{Literature Cited}

(1) Amyot, M.; Mierle, G.; Lean, D. R. S.; McQueen, D. J. Sunlight- induced formation of dissolved gaseous mercury in lake waters. Environ. Sci. Technol. 1994, 28, 2366-2371.

(2) Lacerda, L. D.; Pfeiffer, W. C. Mercury from gold mining in Amazon environmentsan overview. Quim. Nova 1992,55, $283-294$.

(3) Stoffers, P.; Hannington, M.; Wright, I.; Herzig, P.; deRonde, C. Elemental mercury at submarine hydrothermal vents in the Bay of Plenty, Taupo volcanic zone, New Zealand. Geology 1999, 10, 931-934.

(4) Mason, R. P.; Fitzgerald, W. F. Alkylmercury species in the equatorial Pacific. Nature 1990, $347,457$.

(5) Vandal, G. M.; Mason, R. P.; Fitzgerald, W. F. Cycling of volatile mercury in temperate lakes. Water, Air, Soil Pollut. 1991, 56, 791803.

(6) Mason, R. P.; Fitzgerald, W. F.; Hurley, J.; Hanson, A. K., Jr.; Donaghay, P. L.; Sieburgh, J. M. Mercury biogeochemical cycling in a stratified estuary. Limnol. Oceanogr. 1993, 38, 1227-1241.

(7) Mason, R. P.; Sheu, G.-R. Role of the ocean in the global mercury cycle. Global Biogeochem. Cycles 2002, 16, 1093, doi: 10.1029/ $2001 \mathrm{~GB} 001440$.

(8) Alberts, J. J.; Schindler, J. E.; Miller, R. W. Elemental mercury evolution mediated by humic acid. Science 1974, 184, 895-897.

(9) Ben-Bassat, D.; Mayer, A. M. Light-induced $\mathrm{Hg}$ volatilization and $\mathrm{O}_{2}$ evolution in Chlorella and the effect of DCMU and methylamine. Physiol. Plant. 1978, 42, 33-38.

(10) Xiao, Z. F.; Munthe, J.; Stromberg, D.; Lindqvist, O. Photo- chemical behavior of inorganic mercury compounds in aqueous solution. In Mercury PollutionsIntegration and Synthesis; Watras, C. J., Huckabee, J. W., Eds.; Lewis Publishers: Chelsea, MI, 1994.

(11) Amyot, M.; Gill, G. A.; Morel, F. M. M. Production and loss of dissolved gaseous mercury in coastal seawater. Environ. Sci. Technol. 1997, 31, 3606-3611.

(12) Gardfeldt, K.; Jonsson, M. Is bimolecular reduction of $\mathrm{Hg}$ (II) complexes possible in aqueous systems of environmental importance. J. Phys. Chem. A 2003, 107, 4478-4482.

(13) Poulain, A. J.; Amyot, M.; Findlay, D.; Telor, S.; Barkay, T.; Hintelmann, H. Biological and photochemical production of dissolved gaseous mercury in a boreal lake. Limnol. Oceanogr. 2004, 49, 2265-2275.

(14) Amyot, M.; Mierle, G.; Lean, D. R. S.; McQueen, D. J. Effect of solar radiation on the formation of dissolved gaseous mercury in temperate lakes. Geochim. Cosmochim. Acta 1997, 61, 975- 988.

(15) Lalonde, J. D.; Amyot, M; Morel, F. M. M.; Kraepiel, A. Photooxidation of $\mathrm{Hg}(0)$ in artificial and natural waters. Environ. Sci. Technol. 2001, 35, 1367-1372.

(16) Lalonde, J. D.; Amyot, M.; Orvoine, J.; Morel, F. M. M.; Auclair, J. C.; Ariya, P. A. Photoinduced oxidation of $\mathrm{Hg}^{0}(\mathrm{aq})$ in the waters from the St. Lawrence Estuary. Environ. Sci. Technol. 2004, 38, 508514.

(17) Stock, A. Z. Uber Verdampfung, Löslichkeit und Oxidation des metallischen Quecksilbers. Anorg. Allg. Chem. 1934, $217,241-253$.

(18) Clever, H. L.; Johnson, S. A.; Derrick, M. E. The solubility of mercury and some sparingly soluble mercury salts in water and aqueous electrolyte solutions. J. Phys. Chem. Ref. Data 1985, 14, 631-680.

(19) De Magalhães, A.; Tubino, M. A possible path for mercury in biological systems: the oxidation of metallic mercury by molecular oxygen in aqueous solutions. Sci. Total Environ. 1995, 170, 229-239.

(20) Yamamoto, M. Possible mechanism of elemental mercury oxidation in the presence of SH compounds in aqueous solution. Chemosphere 1995, 31, 2791-2798.

(21) Yamamoto, M. Simulation of elemental mercury oxidation in the presence of chloride ion in aquatic environments. Chemo- sphere 1996, 32, 1217-1224.

(22) Gill, G. A.; Bruland, K. W. Mercury speciation in surface freshwater systems in California and other areas. Environ. Sci. Technol. 1990, 24, 1392-1400. 
This document is the unedited Author's version of a Submitted Work that was subsequently accepted for publication in 'ACS Sustainable Chemistry \& Engineering', copyright ( $\odot$ American Chemical Society after peer review. To access the final edited and published version see:https://pubs.acs.org/doi/abs/10.1021/es035444k

(23) Sanemasa, I.; Kobayashi, T.; Deguchi, T.; Nagai, H. The disproportionation constants of Hg(I) in dilute solutions. Bull. Chem. Soc. Jpn. 1983, 56, 1231-1232.

(24) Wetzel, R. G. Limnology; Saunders College Publishing: Phila- delphia, 1983. 